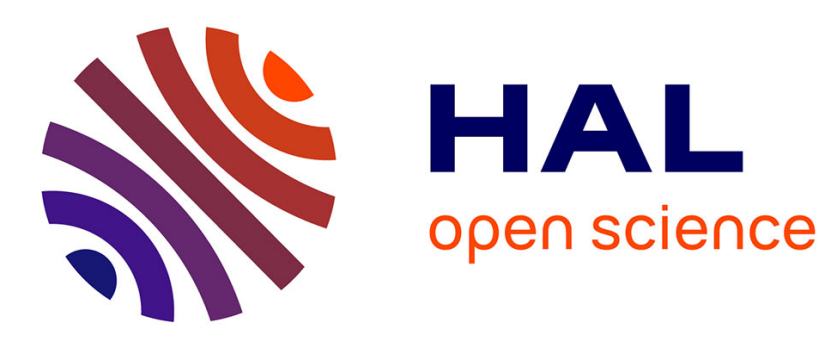

\title{
Study of the transport of thyroid hormone by transporters of the SLC10 family
}

\author{
W. Edward Visser, Wing S. Wong, Alies A.A. van Mullem, Edith C.H. \\ Friesema, Joachim Geyer, Theo J. Visser
}

\section{- To cite this version:}

W. Edward Visser, Wing S. Wong, Alies A.A. van Mullem, Edith C.H. Friesema, Joachim Geyer, et al.. Study of the transport of thyroid hormone by transporters of the SLC10 family. Molecular and Cellular Endocrinology, 2009, 315 (1-2), pp.138. 10.1016/j.mce.2009.08.003 . hal-00547654

\section{HAL Id: hal-00547654 \\ https://hal.science/hal-00547654}

Submitted on 17 Dec 2010

HAL is a multi-disciplinary open access archive for the deposit and dissemination of scientific research documents, whether they are published or not. The documents may come from teaching and research institutions in France or abroad, or from public or private research centers.
L'archive ouverte pluridisciplinaire HAL, est destinée au dépôt et à la diffusion de documents scientifiques de niveau recherche, publiés ou non, émanant des établissements d'enseignement et de recherche français ou étrangers, des laboratoires publics ou privés. 


\section{Accepted Manuscript}

Title: Study of the transport of thyroid hormone by transporters of the SLC10 family

Authors: W. Edward Visser, Wing S. Wong, Alies A.A. van Mullem, Edith C.H. Friesema, Joachim Geyer, Theo J. Visser

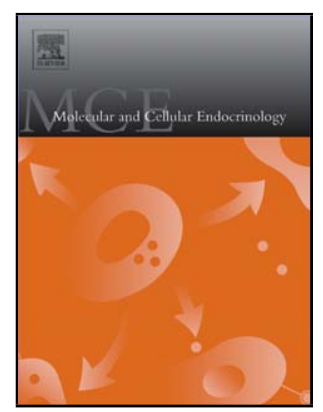

PII:

S0303-7207(09)00406-7

DOI: doi:10.1016/j.mce.2009.08.003

Reference: MCE 7283

To appear in: $\quad$ Molecular and Cellular Endocrinology

Received date: $\quad$ 13-5-2009

Revised date: 22-7-2009

Accepted date: $\quad$ 5-8-2009

Please cite this article as: Visser, W.E., Wong, W.S., van Mullem, A.A.A., Friesema, E.C.H., Geyer, J., Visser, T.J., Study of the transport of thyroid hormone by transporters of the SLC10 family, Molecular and Cellular Endocrinology (2008), doi:10.1016/j.mce.2009.08.003

This is a PDF file of an unedited manuscript that has been accepted for publication. As a service to our customers we are providing this early version of the manuscript. The manuscript will undergo copyediting, typesetting, and review of the resulting proof before it is published in its final form. Please note that during the production process errors may be discovered which could affect the content, and all legal disclaimers that apply to the journal pertain. 


\section{Study of the transport of thyroid hormone by transporters of the SLC10 family}

2

3 W. Edward Visser ${ }^{1}$, Wing S. Wong ${ }^{1}$, Alies A.A. van Mullem ${ }^{1}$, Edith C.H. Friesema ${ }^{1}$, Joachim Geyer ${ }^{2}$ 4 and Theo J. Visser ${ }^{1}$.

5

$6 \quad{ }^{1}$ Department of Internal Medicine

7 Erasmus University Medical Center

8 Dr Molewaterplein 50

93015 GE Rotterdam

10 The Netherlands

11 Phone: +31-10-7043415

12 Fax: $+31-10-7035430$

13

$14 \quad{ }^{2}$ Institute of Pharmacology and Toxicology

15 Justus Liebig University of Giessen

16 Giessen

17 Germany

18

19 Corresponding author: Theo J. Visser (t.j.visser@erasmusmc.nl)

20

Key words

22 SLC10 family; SLC10A1; NTCP; transporter; thyroid hormone; iodothyronine (sulfates); 23 taurocholate; CRYM, mu-crystallin

24

25

Grants

26 WEV and ECHF are supported by the Netherlands Organization for Scientific Research (NWO grant 27 9120.6093).

28

\section{Disclosure statement}

30 The authors have nothing to disclose.

31 


\section{Abstract}

Transport of (sulfated) iodothyronines across the plasma membrane is required for their 3 intracellular metabolism. Rat $\mathrm{Na}^{+} /$taurocholate cotransporting polypeptide (Ntcp; Slc10a1) has been

4 identified as an important transporter protein. We demonstrate that among the 7 members of the solute 5 carrier family SLC10, only human SLC10A1 mediates sodium-dependent transport of the 6 iodothyronine T4 and iodothyronine sulfates T3S and T4S. In contrast to SLC10A2-7, cells co7 expressing SLC10A1 and the deiodinase D1 demonstrate a dramatic increase in T3S and T4S 8 metabolism. The SLC10A1 substrates taurocholate, DHEAS and E3S inhibit T3S and T4S transport. 9 Furthermore, co-transfection of SLC10A1 with CRYM, a well-known intracellular iodothyronine10 binding protein, results in an enhanced intracellular accumulation of T3S and T4S, indicating that 11 CRYM binds iodothyronine sulfates.

12 The present findings indicate that the liver-specific transporter SLC10A1 transports (sulfated) 13 iodothyronines, thereby increasing their intracellular availability. Therefore, SLC10A1 may fulfill a 14 critical step in providing liver D1 with iodothyronine sulfates for rapid degradation. 
Introduction

Thyroid hormone $(\mathrm{TH})$ is essential for numerous metabolic processes. A principal regulatory role to achieve appropriate intracellular TH concentrations is reserved for the 3 deiodinating enzymes. The deiodinases D1 and D2 activate TH by converting the prohormone T4 to T3, whereas D3 has an inactivating function by deiodination of $\mathrm{T} 4$ and $\mathrm{T} 3$ to transcriptionally inactive rT3 and 3,3'-T2, respectively [1]. Although deiodination is regarded as the major pathway for TH metabolism, a number of alternate pathways have physiological relevance [2]. Sulfoconjugation is catalyzed by sulfotransferases, which transfer a sulfate group to the phenolic ring of iodothyronines. Although the thyromimetic activity of iodothyronine sulfates is limited, these compounds may have biological relevance $[3,4]$. It is known that sulfation accelerates degradation of the iodothyronines by D1 [5]. On the other hand, biologically inactive sulfated TH may serve as a pool contributing to the availability of $\mathrm{TH}$, because, for example, bioactive T3 may be recovered from T3S by sulfatases in selective tissues [2].

Deiodination of iodothyronines and their sulfates takes place intracellularly. Therefore, transport of (sulfated) iodothyronines across the plasma membrane, which is facilitated by transporter proteins, is required [6]. However, only a few proteins are known to be active and specific iodothyronine transporters [6]. Previously, we found that Xenopus laevis oocytes injected with cRNA coding for rat $\mathrm{Na}^{+}$/taurocholate cotransporting polypeptide (Ntcp), currently known as Slc10a1, facilitated uptake of iodothyronines and their sulfates [7]. In addition to the known human ileal apical sodium-dependent bile acid transporter (ASBT; SLC10A2), five new members of the SLC10 family were identified recently [8-10]. However, SLC10A3, 4, 5 and 7 are orphan transporters for which no substrates have been identified.

For several TH transporters, it has been shown that different members of the same transporter family, facilitate TH transport, such as monocarboxylate transporter (MCT) 8 and MCT10 of the MCT family, and multiple members of the organic anion transporting polypeptide (OATP) family, including OATP1A2, 1C1, 1B1 and 1B3 [11-14]. Therefore, in the present study we investigate in transfected HEK293 and COS1 cells which members of the SLC10 family, in addition to SLC10A1, may transport (sulfated) iodothyronines, whether or not in addition to already known substrates.

\section{Materials and Methods}

Materials

$\left[{ }^{125} \mathrm{I}\right] \mathrm{T} 3,\left[{ }^{125} \mathrm{I}\right] \mathrm{T} 4,\left[{ }^{125} \mathrm{I}\right] \mathrm{T} 3 \mathrm{~S}$ and $\left[{ }^{125} \mathrm{I}\right] \mathrm{T} 4 \mathrm{~S}$ were synthesized as described [15]. $\left[{ }^{3} \mathrm{H}\right]$ taurocholate $\left(\left[{ }^{3} \mathrm{H}\right] \mathrm{TC}\right)$ and $\left[{ }^{3} \mathrm{H}\right]$ estrone-1-sulfate $\left(\left[{ }^{3} \mathrm{H}\right] \mathrm{E} 1 \mathrm{~S}\right)$ were purchased from Perkin Elmer (Boston, MA). Unlabeled iodothyronines were obtained from Henning (Berlin, Germany). All other compounds were purchased from Sigma (St. Louis, MO). 
Cloning

Human (h) SLC10A1 (kindly provided by prof. dr. P.J. Meier, Zurich, Switzerland), hSLC10A2 (obtained from Open Biosystems, Huntsville, AL) and hSLC10A3 (kindly provided by dr. T. Abe, Japan) were subcloned in pcDNA3 (Invitrogen, Carlsbad, CA). The coding regions of rat (r) Slc10a4 and hSLC10A5-7 were cloned in pcDNA5 (Invitrogen, Carlsbad, CA) as described $[9,10,16,17]$. rSlc10a4 was used as the hSLC10A4 clone was not available at the time of our experiments. Human $\mu$-crystallin (hCRYM) was cloned in the pSG5 vector (Stratagene, La Jolla, CA) [12] and rD1 in pcDNA3 [18].

\section{Transport studies}

For transport experiments equal numbers of HEK293 and COS1 cells were seeded in 6-well culture dishes in DMEM/F12 medium supplemented with 9\% heat-inactivated FBS and $100 \mathrm{nM}$ sodium selenite. This results in very similar amounts of cellular protein as determined by a standard Bradford assay. At 75\% confluency, cells were transfected with 500 ng pcDNA3.hSLC10A1-3, pcDNA5.rSlc10a4, or pcDNA5.hSLC10A5-7 alone or co-transfected with 500 ng pSG5.hCRYM. 48 $\mathrm{h}$ after transfection, cells were washed with incubation medium (Dulbecco's PBS containing $0.1 \% \mathrm{D}$ glucose with or without $0.1 \% \mathrm{BSA}$ ). Uptake was tested by incubation of the cells for 5-30 min at $37^{\circ} \mathrm{C}$ with $1 \mathrm{nM}\left(1 \times 10^{5} \mathrm{cpm}\right)\left[{ }^{125} \mathrm{I}\right] \mathrm{T} 3,\left[{ }^{125} \mathrm{I}\right] \mathrm{T} 4,\left[{ }^{125} \mathrm{I}\right] \mathrm{T} 3 \mathrm{~S}$ or $\left[{ }^{125} \mathrm{I}\right] \mathrm{T} 4 \mathrm{~S}$ in $1.5 \mathrm{ml}$ incubation medium, in the absence or presence of taurocholate (TC), dehydroepiandrosterone sulfate (DHEAS) or estrone-3sulfate (E3S). After incubation, cells were washed with incubation medium, lyzed with $0.1 \mathrm{M} \mathrm{NaOH}$, and counted in a gamma counter. Uptake of $\left[{ }^{3} \mathrm{H}\right] \mathrm{TC}$ and $\left[{ }^{3} \mathrm{H}\right] \mathrm{E} 1 \mathrm{~S}$ by the SLC10 carriers was tested in a similar manner by incubation of cells for 30 min with $1 \mu \mathrm{M}\left[{ }^{3} \mathrm{H}\right] \mathrm{TC}$ or $0.1 \mu \mathrm{M}\left[{ }^{3} \mathrm{H}\right] \mathrm{E} 1 \mathrm{~S}$ in $1.5 \mathrm{ml}$ incubation medium. Cells were lyzed with $0.1 \%$ SDS and subsequently counted for radioactivity.

For measurement of efflux, cells were loaded for $30 \mathrm{~min}$ with $1.5 \mathrm{ml}$ incubation medium containing $1 \mathrm{nM}\left(1 \times 10^{5} \mathrm{cpm}\right)\left[{ }^{125} \mathrm{I}\right] \mathrm{T} 3 \mathrm{~S}$ or $\left[{ }^{125} \mathrm{I}\right] \mathrm{T} 4 \mathrm{~S}$. After removal of the medium, cells were briefly washed and incubated for 5-30 min with incubation medium (containing 1\% BSA) without ligand. Finally, medium was removed, and cells were washed with incubation medium, lyzed with $0.1 \mathrm{M}$ $\mathrm{NaOH}$ and counted in a gamma counter.

To evaluate $\mathrm{Na}^{+}$-dependence of transport, $1 \mathrm{nM}\left[{ }^{125} \mathrm{I}\right] \mathrm{T} 4,\left[{ }^{125} \mathrm{I}\right] \mathrm{T} 3 \mathrm{~S},\left[{ }^{125} \mathrm{I}\right] \mathrm{T} 4 \mathrm{~S}$ or $1 \mu \mathrm{M}\left[{ }^{3} \mathrm{H}\right] \mathrm{TC}$ were incubated with the cells in a medium containing $142.9 \mathrm{mM} \mathrm{NaCl}, 4.7 \mathrm{mM} \mathrm{KCl}, 1.2 \mathrm{mM} \mathrm{MgSO}_{4}$, $1.2 \mathrm{mM} \mathrm{KH}_{2} \mathrm{PO}_{4}, 1.8 \mathrm{mM} \mathrm{CaCl}_{2}, 20 \mathrm{mM}$ HEPES and 0.1\% BSA (pH 7.4) or in medium where $\mathrm{Na}^{+}$ was replaced with an equimolar amount of choline.

\section{Metabolism studies}

COS1 cells were cultured in 24-well culture dishes and transfected with 100 ng pcDNA3.rD1 and 100 ng pcDNA3, pcDNA3.hSLC10A1-3, pcDNA5.rSlc10a4 or pcDNA5.hSLC10A5-7. After $48 \mathrm{~h}$ transfection, cells were incubated for $24 \mathrm{~h}$ at $37^{\circ} \mathrm{C}$ with $1 \mathrm{nM}\left(5 \times 10^{5} \mathrm{cpm}\right)\left[{ }^{125} \mathrm{I}\right] \mathrm{T} 3 \mathrm{~S}$ or $\left[{ }^{125} \mathrm{I}\right] \mathrm{T} 4 \mathrm{~S}$ in 
$10.25 \mathrm{ml} \mathrm{DMEM} / \mathrm{F} 12$. After incubation, medium was harvested and analyzed by HPLC as described

2 previously [18].

Statistical analysis

Results are presented as the means and ranges of duplicate determinations in a representative experiment $(n=2-4)$. Statistical significance was determined using the Student's $t$ test.

\section{Results}

Previously, HEK293 cells as well as COS1 cells have been used to study various members of the SLC10 family $[9,10,16,17,19]$. Therefore, we used both cell lines in our experiments. We first assessed uptake of (sulfated) iodothyronines in HEK293 cells. No induction of T3 uptake was observed in cells transfected with any of the SLC10 transporters (Fig. 1A and data not shown), whereas an insignificant increase in T4 uptake was seen if SLC10A1 was expressed (Fig. 1B). T3S and T4S uptake was largely induced by SLC10A1 in contrast to the other SLC10 transporters (Fig. 1C,D and data not shown). Figure 1E shows a clear time-dependent increase in the uptake of T3S and T4S in cells expressing SLC10A1. As transporters may facilitate not only substrate uptake but also efflux, we investigated whether SLC10A1 mediates T3S and T4S export. No difference in efflux of T3S and T4S was observed between cells expressing low versus high levels of SLC10A1 (Fig. 1F,G), suggesting that SLC10A1 does not facilitate the efflux of these substrates. Re-uptake of T3S and T4S does not play a major role, as $1 \%$ BSA in the efflux medium efficiently blocks uptake of sulfated iodothyronines (data not shown). We confirmed that SLC10A1 transports TC in a $\mathrm{Na}^{+}$-dependent manner (data not shown). As anticipated, uptake of T4 (data not shown), T3S (Fig. 1H) and T4S (Fig. 1I) is also a $\mathrm{Na}^{+}$-dependent process.

Because HEK293 cells demonstrate a considerable endogenous transport activity of (sulfated) iodothyronines, we also tested transfected COS1 cells for uptake of different ligands. To confirm that COS1 cells transfected with cDNA coding for each of the SLC10 family members are appropriate to study transport function, uptake was studied of TC, a known substrate for SLC10A1 and 2. Fig. 2 shows a 69-fold and 6-fold increase of TC uptake in cells transfected with SLC10A1 and 2, respectively, whereas the other SLC10 members did not demonstrate any transport activity. Furthermore, E1S was only transported by SLC10A1 and 6 (data not shown). These results agree with the existing evidence, indicating that this cell expression system is appropriate to study transporter characteristics. Because functional expression can only be demonstrated for SLC10A1, 2 and 6, transport studies are only shown for these transporters.

Then, we examined the uptake of the iodothyronines T3 and T4 by transfected COS cells. Fig. 3A,B clearly shows that only SLC10A1 is modestly capable of transporting T4, whereas T3 is not transported by any of the SLC10 proteins. In contrast to the unconjugated iodothyronines, the T3S and 
uptake is more pronounced if cells are co-transfected with CRYM, a cytosolic binding protein with high affinity for iodothyronines. In contrast to SLC10A1, SLC10A2-7 do not transport the tested iodothyronine sulfates (Fig. 3C,D and data not shown).

To assess whether SLC10A1-mediated transport of iodothyronine sulfates facilitates their intracellular metabolism by D1, cells were co-transfected with SLC10A1-7 and D1. Subsequently, cells were incubated for $24 \mathrm{~h}$ with T3S or T4S and medium radioactivity was analyzed. Intracellular T3S and T4S metabolism dramatically increased in cells co-expressing SLC10A1 and D1 (data not shown). In contrast, in cells co-expressing any of the other SLC10 proteins with D1, negligible metabolite production was seen. In the analyzed medium, only the substrate (T3S or T4S) or I' was observed, but no intermediate metabolites.

In an attempt to calculate kinetic parameters for T3S and T4S uptake by SLC10A1, we incubated cells transfected with SLC10A1 with 0.01-5 $\mu \mathrm{M}$ of each substrate. No clear saturation was observed for T3S and T4S uptake at concentrations of up to $5 \mu \mathrm{M}$ (data not shown). It was not possible to study the effects of higher concentrations of T3S and T4S due to the limited availability of these compounds caused by the low solubility of the iodothyronines used for their synthesis.

The previous experiments indicate that of all SLC10 transporters only SLC10A1 specifically transports T3S and T4S. Because SLC10A1 also facilitates uptake of bile acids and steroid sulfates, we studied the inhibitory effects of TC, DHEAS and E3S on SLC10A1-mediated transport of T3S and T4S. As the tested compounds may interfere with T3S or T4S binding to BSA, we used incubation medium without BSA to directly test the interactions with SLC10A1. At $50 \mu \mathrm{M}$ concentrations, SLC10A1-mediated T3S and T4S transport is reduced to $\sim 20 \%$ by TC, whereas weaker inhibitory effects are observed by DHEAS and E3S (Fig. 4).

Finally, we pursued the interesting observation that co-transfection of CRYM, which has affinity for the iodothyronines T4, T3, 3,5-T2 and, less so, rT3 [20,21], enhanced net cellular uptake of iodothyronine sulfates (Fig. 3). Therefore, we tested the hypothesis that CRYM binds intracellular T3S and T4S, resulting in a diminished T3S and T4S efflux. This mechanism would explain the increased accumulation of the iodothyronine sulfates in cells co-expressing SLC10A1 and CRYM. We studied efflux of T3S and T4S after 30 min incubation with these ligands in cells transfected with SLC10A1 alone or in combination with CRYM. Fig. 5 demonstrates that in the absence of CRYM, T3S and T4S are rapidly released from the cells. In contrast, T3S and T4S efflux was diminished significantly in cells co-expressing SLC10A1 and CRYM. HPLC analyis of the cell contents detected solely the incubated substrates T3S or T4S, but no metabolites (data not shown). This indicates that CRYM binds intracellular T3S and T4S and, thus, largely prevents their efflux.

\section{Discussion}

NTCP (SLC10A1) and ASBT (SLC10A2), which were the SLC10 family members discovered 
only the sodium-dependent organic anion transporter (SOAT; SLC10A6) has been shown to transport steroid sulfates but not bile acids, whereas SLC10A3-7 remained orphan carriers [8-10]. The hypothesis to test which members of the SLC10 family transport iodothyronies is based on the observation that rSlc10a1 transports (sulfated) iodothyronines and that in different transporter families several members, with varying degrees of similarity, transport iodothyronines [7,22]. Therefore, we investigated which members of this SLC10 transporter family are capable of mediating transport of (sulfated) iodothyronines.

We directly compared the TC transport by all SLC10 proteins. As expected, only SLC10A1 and 2 facilitated TC uptake. This finding confirms earlier reports that only these two SLC10 proteins transport TC $[8,9]$. In cells expressing SLC10A1, TC uptake is much higher than in cells transfected with SLC10A2. This is also in agreement with earlier observations, which suggested a higher apparent $\mathrm{V}_{\max }$ for TC transport by SLC10A1 compared to SLC10A2 [19].

In subsequent experiments the uptake was studied of the iodothyronines T3 and T4 as well as the iodothyronine sulfates T3S and T4S by cells transfected with cDNA of each of the SLC10 members. Our findings clearly demonstrate the absence of any uptake of the tested iodothyronine derivatives by any of the SLC10 proteins, except for SLC10A1. These negative findings were substantiated by metabolism studies, showing no stimulation of T3S and T4S conversion in cells co-expressing SLC10A2-7 and D1 compared to controls. These data are remarkable as at least some SLC10 proteins appeared to be likely transporters for the tested substrates. For example, despite a marked amino acid similarity (62.8\%) between SLC10A1 and 2, which even have a common substrate (TC), no transport was oberved of the tested iodothyronine derivatives by SLC10A2 [8]. Furthermore, no transport was seen of iodothyronine sulfates by SLC10A6, in spite of the preferential transport of steroid sulfates and the $62.6 \%$ amino acid similarity to SLC10A1 [8]. These data suggest a high degree of substrate specificity in this transporter family. Closely agreeing results were obtained for SLC10A1-7 in different cell lines (HEK293, COS1) and for SLC10A1 and 3 in Xenopus oocytes (Friesema et al., unpublished observations). However, it cannot be excluded that other factors like ancillary proteins are needed for proper function of the transporters which did not demonstrate transport activity in the present study. It should be noted that substrates are only known for SLC10A1, 2 and 6. Thus, the absence of TH transport has only been demonstrated for SLC10A2 and 6. Functional expression of SLC10A3, 4, 5 and 7 could not be established due to the lack of physiological substrates.

Among the SLC10 family, our findings indicate that only SLC10A1 transports the iodothyronine $\mathrm{T} 4$ and iodothyronine sulfates T3S and T4S. As expected, this transport was $\mathrm{Na}^{+}$-dependent, like that of other substrates such as TC and E3S [8]. Our data suggest that a negative charge is important for iodothyronines to be transported by SLC10A1. The phenolic hydroxyl group of T4 dissociates (becomes negatively charged) above $\mathrm{pH} 6.5$, whereas that of $\mathrm{T} 3$ only above $\mathrm{pH} 8.5$. The highly negative charge of the sulfate group substantiates the importance of ionisation for substrate 
1 T3S and T4S metabolism is observed. This indicates that SLC10A1 increases the intracellular availability of $\mathrm{T} 3 \mathrm{~S}$ and $\mathrm{T} 4 \mathrm{~S}$. It was not possible to calculate kinetic parameters for $\mathrm{T} 3 \mathrm{~S}$ and $\mathrm{T} 4 \mathrm{~S}$ transport.

The fold increase in uptake induced by hSLC10A1 was larger for iodothyronine sulfates than for the native iodothyronines (due to lower background rather than larger absolute increase). Our findings suggest that hSLC10A1 plays an important role in the uptake of iodothyronine sulfates into the liver in vivo where they are rapidly degraded by D1 [5]. This is in line with the observation that SLC10A1 mainly facilitates uptake, but not efflux. In our T3S and T4S metabolism assays, we observed only $\mathrm{I}^{-}$ as a metabolite, which underlines that these compounds and their intermediates (T2S and rT3S) are converted very rapidly. Therefore, SLC10A1 may fulfill a critical step in providing liver D1 with iodothyronine sulfates for rapid degradation, thereby contributing to the low circulating levels of iodothyronine sulfates in adulthood.

An opposite situation may exist in fetal life. It is known that serum iodothyronine sulfate levels are much higher in the fetus than in adults, which may serve as an additional regulatory mechanism for optimizing tissue-specific TH bioavailability $[23,24]$. Several factors, like low D1 activity in fetal life, may contribute to these increased levels of fetal iodothyronine sulfates. However, mouse and rat Slc10a1 expression dramatically increases from low levels before birth to high levels at birth $[25,26]$. In human fetal lever, the expression of SLC10A1 is almost undetectable [27]. The low expression of human SLC10A1 during fetal development may result in a low uptake of iodothyronine sulfates into the liver. This will diminish the supply of iodothyronine sulfates to hepatic D1, resulting in a decrease of clearance of these compounds. This indicates that the metabolism of iodothyronine sulfates is not only regulated by D1 expression but also depends on the level of transporter proteins. This is supported by recent observations in which some members of the OATP family are also capable of transporting T3S and T4S [14,28]. The contribution of the different transporters (SLC10A1 versus OATPs) to T3S and T4S transport requires further studies.

The SLC10A1 substrates TC, DHEAS and E3S were able to inhibit T3S and T4S transport, of which TC exerted the most potent inhibitory effects. Recently, bile acids were shown to induce THmediated metabolism via a signalling pathway involving D2 [29]. Our observations that iodothyronine sulfates are transported by the predominant hepatic bile acid transporter SLC10A1 may add a new dimension to the concept connecting bile acids and TH in the control of energy expenditure. When serum bile acids concentrations increase, for example after a meal [30], uptake of iodothyronine sulfates by SLC10A1 will diminish, thereby preventing hepatic clearance of iodothyronine sulfates. As a consequence, increased serum concentrations of iodothyronine sulfates may be available for desulfation in extrahepatic tissues, resulting in increased bioactive TH concentrations and, thus, increased metabolism in these tissues. These effects would be most effective in cells possessing both a T3S/T4S transporter and a sulfatase. It should be stressed that the physiological importance remains 
1 Therefore, the degree of contribution to biologically active $\mathrm{TH}$ via desulfation of iodothyronine 2 sulfates remains uncertain.

We performed several experiments in which we studied the effect of co-transfection with CRYM on the uptake and efflux of iodothyronine sulfates. Our observations that CRYM prevents the efflux of the tested substrates may suggest that CRYM binds iodothyronine sulfates. This is substantiated by the finding that in these experiments cellular T3S and T4S remained intact. Originally, CRYM was reported to bind to native iodothyronines in the presence (T3>T4>rT3) and also the absence $(3,5-\mathrm{T} 2)$ of NADPH [20,21]. Subsequent studies mainly focused on the role of CRYM in the intracellular binding of T3 [32-34]. Our findings may implicate an extension of the role of CRYM to function as a binding protein for iodothyronine sulfates. If so, one would speculate that it may direct the iodothyronine sulfates to intracellular targets, for example D1. However, it should be noted that kinetic properties of CRYM were not directly studied. Therefore, additional studies are required to elucidate the in vivo relevance of this apparent novel function of CRYM.

In conclusion, we provide evidence that also human SLC10A1 transports iodothyronine sulfates, in contrast with SLC10A2-7. In addition, our results suggest that CRYM is capable of binding iodothyronine sulfates. The present paper supports the notion that $\mathrm{TH}$ regulates metabolism via different pathways. Further studies are required to investigate to which extent our findings are relevant for physiology.

\section{Acknowledgements}

We thank Wim Klootwijk (Erasmus MC) for synthesis and labeling of T3, T4, T3S and T4S.

\section{Grants}

WEV and ECHF are supported by the Netherlands Organization for Scientific Research (NWO grant 9120.6093).

\section{Disclosure statement}

The authors have nothing to disclose. 


\section{References}

[1] Bianco, A.C. and Kim, B.W. (2006) Deiodinases: implications of the local control of thyroid hormone action. J Clin Invest 116, 2571-9.

[2] Wu, S.Y., Green, W.L., Huang, W.S., Hays, M.T. and Chopra, I.J. (2005) Alternate pathways of thyroid hormone metabolism. Thyroid 15, 943-58.

[3] Spaulding, S.W., Smith, T.J., Hinkle, P.M., Davis, F.B., Kung, M.P. and Roth, J.A. (1992) Studies on the biological activity of triiodothyronine sulfate. J Clin Endocrinol Metab 74, 1062-7.

[4] Santini, F., Hurd, R.E., Lee, B. and Chopra, I.J. (1993) Thyromimetic effects of 3,5,3'-triiodothyronine sulfate in hypothyroid rats. Endocrinology 133, 105-10.

[5] Otten, M.H., Mol, J.A. and Visser, T.J. (1983) Sulfation preceding deiodination of iodothyronines in rat hepatocytes. Science 221, 81-3.

[6] Visser, W.E., Friesema, E.C., Jansen, J. and Visser, T.J. (2008) Thyroid hormone transport in and out of cells. Trends Endocrinol Metab 19, 50-56.

[7] Friesema, E.C., Docter, R., Moerings, E.P., Stieger, B., Hagenbuch, B., Meier, P.J., Krenning, E.P., Hennemann, G. and Visser, T.J. (1999) Identification of thyroid hormone transporters. Biochem Biophys Res Commun 254, 497-501.

[8] Geyer, J., Wilke, T. and Petzinger, E. (2006) The solute carrier family SLC10: more than a family of bile acid transporters regarding function and phylogenetic relationships. Naunyn Schmiedebergs Arch Pharmacol 372, 413-31.

[9] Godoy, J.R., Fernandes, C., Doring, B., Beuerlein, K., Petzinger, E. and Geyer, J. (2007) Molecular and phylogenetic characterization of a novel putative membrane transporter (SLC10A7), conserved in vertebrates and bacteria. Eur J Cell Biol 86, 445-60.

[10] Geyer, J., Fernandes, C.F., Doring, B., Burger, S., Godoy, J.R., Rafalzik, S., Hubschle, T., Gerstberger, R. and Petzinger, E. (2008) Cloning and molecular characterization of the orphan carrier protein Slc10a4: Expression in cholinergic neurons of the rat central nervous system. Neuroscience.

[11] Friesema, E.C., Ganguly, S., Abdalla, A., Manning Fox, J.E., Halestrap, A.P. and Visser, T.J. (2003) Identification of monocarboxylate transporter 8 as a specific thyroid hormone transporter. J Biol Chem 278, 40128-35.

[12] Friesema, E.C., Jansen, J., Jachtenberg, J.W., Visser, W.E., Kester, M.H. and Visser, T.J. (2008) Effective cellular uptake and efflux of thyroid hormone by human monocarboxylate transporter 10 (MCT10). Mol Endocrinol 22, 1357-69.

[13] Pizzagalli, F., Hagenbuch, B., Stieger, B., Klenk, U., Folkers, G. and Meier, P.J. (2002) Identification of a novel human organic anion transporting polypeptide as a high affinity thyroxine transporter. Mol Endocrinol 16, 2283-96.

[14] van der Deure, W.M., Friesema, E.C., de Jong, F.J., de Rijke, Y.B., de Jong, F.H., Uitterlinden, A.G., Breteler, M.M., Peeters, R.P. and Visser, T.J. (2008) OATP1B1: an important factor in hepatic thyroid hormone and estrogen transport and metabolism. Endocrinology 149, 1495-701.

[15] Mol, J.A. and Visser, T.J. (1985) Synthesis and some properties of sulfate esters and sulfamates of iodothyronines. Endocrinology 117, 1-7.

[16] Geyer, J., Doring, B., Meerkamp, K., Ugele, B., Bakhiya, N., Fernandes, C.F., Godoy, J.R., Glatt, H. and Petzinger, E. (2007) Cloning and functional characterization of human sodium-dependent organic anion transporter (SLC10A6). J Biol Chem 282, 19728-41.

[17] Fernandes, C.F., Godoy, J.R., Doring, B., Cavalcanti, M.C., Bergmann, M., Petzinger, E. and Geyer, J. (2007) The novel putative bile acid transporter SLC10A5 is highly expressed in liver and kidney. Biochem Biophys Res Commun 361, 26-32. 
[18] Friesema, E.C., Kuiper, G.G., Jansen, J., Visser, T.J. and Kester, M.H. (2006) Thyroid hormone transport by the human monocarboxylate transporter 8 and its rate-limiting role in intracellular metabolism. Mol Endocrinol 20, 2761-72.

[19] Craddock, A.L., Love, M.W., Daniel, R.W., Kirby, L.C., Walters, H.C., Wong, M.H. and Dawson, P.A. (1998) Expression and transport properties of the human ileal and renal sodium-dependent bile acid transporter. Am J Physiol 274, G157-69.

[20] Vie, M.P., Evrard, C., Osty, J., Breton-Gilet, A., Blanchet, P., Pomerance, M., Rouget, P., Francon, J. and Blondeau, J.P. (1997) Purification, molecular cloning, and functional expression of the human nicodinamide-adenine dinucleotide phosphateregulated thyroid hormone-binding protein. Mol Endocrinol 11, 1728-36.

[21] Moreno, M., Silvestri, E., Lombardi, A., Visser, T.J., Goglia, F. and Lanni, A. (2003) Identification of 3,5-diiodo-L-thyronine-binding proteins in rat liver cytosol by photoaffinity labeling. Endocrinology 144, 2297-303.

[22] Visser, W.E., Friesema, E.C., Jansen, J. and Visser, T.J. (2008) Thyroid hormone transport in and out of cells. Trends Endocrinol Metab 19, 50-6.

[23] Chopra, I.J., Wu, S.Y., Teco, G.N. and Santini, F. (1992) A radioimmunoassay for measurement of 3,5,3'-triiodothyronine sulfate: studies in thyroidal and nonthyroidal diseases, pregnancy, and neonatal life. J Clin Endocrinol Metab 75, 189-94.

[24] Santini, F., Cortelazzi, D., Baggiani, A.M., Marconi, A.M., Beck-Peccoz, P. and Chopra, I.J. (1993) A study of the serum 3,5,3'-triiodothyronine sulfate concentration in normal and hypothyroid fetuses at various gestational stages. J Clin Endocrinol Metab 76, 1583-7.

[25] Cheng, X., Buckley, D. and Klaassen, C.D. (2007) Regulation of hepatic bile acid transporters Ntcp and Bsep expression. Biochem Pharmacol 74, 1665-76.

[26] Boyer, J.L., Hagenbuch, B., Ananthanarayanan, M., Suchy, F., Stieger, B. and Meier, P.J. (1993) Phylogenic and ontogenic expression of hepatocellular bile acid transport. Proc Natl Acad Sci U S A 90, 435-8.

[27] Chen, H.L., Liu, Y.J., Feng, C.H., Wu, C.Y., Shyu, M.K., Yuan, R.H. and Chang, M.H. (2005) Developmental expression of canalicular transporter genes in human liver. J Hepatol 43, 472-7.

[28] van der Deure, W.M., Hansen, P.S., Peeters, R.P., Kyvik, K.O., Friesema, E.C., Hegedus, L. and Visser, T.J. (2008) Thyroid hormone transport and metabolism by OATP1C1 and consequences of genetic variation. Endocrinology 149, 5307-14.

[29] Watanabe, M., Houten, S.M., Mataki, C., Christoffolete, M.A., Kim, B.W., Sato, H., Messaddeq, N., Harney, J.W., Ezaki, O., Kodama, T., Schoonjans, K., Bianco, A.C. and Auwerx, J. (2006) Bile acids induce energy expenditure by promoting intracellular thyroid hormone activation. Nature 439, 484-9.

[30] Everson, G.T. (1987) Steady-state kinetics of serum bile acids in healthy human subjects: single and dual isotope techniques using stable isotopes and mass spectrometry. J Lipid Res 28, 238-52.

[31] Eelkman Rooda, S.J., Kaptein, E. and Visser, T.J. (1989) Serum triiodothyronine sulfate in man measured by radioimmunoassay. J Clin Endocrinol Metab 69, 552-6.

[32] Suzuki, S., Mori, J., Kobayashi, M., Inagaki, T., Inaba, H., Komatsu, A., Yamashita, K., Takeda, T., Miyamoto, T., Ichikawa, K. and Hashizume, K. (2003) Cell-specific expression of NADPH-dependent cytosolic 3,5,3'-triiodo-L-thyronine-binding protein (p38CTBP). Eur J Endocrinol 148, 259-68.

[33] Suzuki, S., Suzuki, N., Mori, J., Oshima, A., Usami, S. and Hashizume, K. (2007) micro-Crystallin as an intracellular 3,5,3'-triiodothyronine holder in vivo. Mol Endocrinol 21, 885-94. 
[34] Suzuki, S., Mori, J. and Hashizume, K. (2007) mu-crystallin, a NADPH-dependent T(3)-binding protein in cytosol. Trends Endocrinol Metab 18, 286-9.

3

4 


\section{Figure legends}

Fig. 1. Uptake of (sulfated) iodothyronines in HEK293 cells transfected with hCRYM and hSLC10A1, hSLC10A2 and hSLC10A6. Uptake was measured after 30 min incubation with $1 \mathrm{nM}$ T3 (A), T4 (B), T3S (C) or T4S (D) in D-PBS containing $0.1 \%$ glucose and $0.1 \%$ BSA. (E) Uptake of T3S or T4S in HEK293 cells co-transfected with hCRYM and empty vector (circles) or hSLC10A1 (triangles). Uptake was measured after 5, 10 and 30 min incubation with $1 \mathrm{nM}$ T3S (empty symbols) or T4S (filled symbols) in D-PBS containing $0.1 \%$ glucose and $0.1 \%$ BSA. $1 \%$ uptake represents 10 pmol of incubated substrate. Cellular protein amounts to $\sim 3 \mathrm{mg}$ in all wells. Effects of high (500 ng filled circles) versus low (100 ng - open circles) expression of SLC10A1 on the efflux of T3S (F) and T4S (G). Cells were incubated for 30 min with $1 \mathrm{nM}$ T3S or T4S in D-PBS containing $0.1 \%$ glucose and $0.1 \%$ BSA. After brief washing, cells were incubated (10-30 min) with efflux medium, containing $1 \%$ BSA, and subsequently processed as described in Materials and Methods. Results (mean \pm range) are corrected for uptake in control-transfected cells. Treated as a first order process, the plot of log cellular T3S or T4S $v s$ time is linear, providing efflux rate constants which are independent of the amount of SLC10A1 expressed. $\mathrm{Na}^{+}$-dependence of the SLC10A1-mediated uptake of T3S $(\mathrm{H})$ and T4S (I). Cells were incubated for 30 min with $1 \mathrm{nM}$ T3S or T4S in sodium chloride medium or sodium-free choline medium. Significances represent mean \pm range obtained in cells expressing a SLC10 transporter versus empty vector. $* \mathrm{P}<0.05 ; * * \mathrm{P}<0.01 ; * * * \mathrm{P}<0.001$.

Fig. 2. Uptake of $1 \mu \mathrm{M}$ TC in COS1 cells transfected with cDNA coding for each of the SLC10 family members. Cells transfected with empty vector were used as controls. Uptake was measured after 30 min TC incubation in D-PBS containing 0.1\% glucose and 0.1\% BSA. 1\% uptake represents uptake of $10 \mathrm{nmol}$ taurocholate. Cellular protein amounts to $\sim 3 \mathrm{mg}$ in all wells. * $\mathrm{P}<0.05 ; * * \mathrm{P}<$ 0.001 .

Fig 3. Uptake of iodothyronines in COS1 cells transfected with cDNA coding for hSLC10A1, hSLC10A2 and hSLC10A6. Uptake was measured after 30 min incubation with $1 \mathrm{nM} \mathrm{T3}$ (A), T4 (B), T3S (C) or T4S (D) in D-PBS containing $0.1 \%$ glucose and $0.1 \%$ BSA. Significances represent mean \pm range obtained in cells expressing a SLC10 transporter versus empty vector, co-transfected with (grey bars) or without (white bars) CRYM. 1\% uptake represents uptake of 10 pmol of incubated substrate. Cellular protein amounts to $\sim 3 \mathrm{mg}$ in all wells. * $\mathrm{P}<0.05 ; * * \mathrm{P}<0.01$; *** $\mathrm{P}<0.001$.

Fig. 4. Influence of $50 \mu \mathrm{M}$ concentrations of TC, DHEAS and E3S on the uptake of T3S (A) and T4S (B) in HEK293 cells transfected with SLC10A1. Cells were incubated for 10 min with $1 \mathrm{nM}$ T3S or T4S in D-PBS containing $0.1 \%$ glucose in the presence of each of the inhibitors. Results are corrected 
1 for uptake in control-transfected cells. 1\% uptake represents uptake of $10 \mathrm{pmol}$ of incubated substrate.

2 Cellular protein amounts to $\sim 3 \mathrm{mg}$ in all wells. $* \mathrm{P}<0.05$.

3

4 Fig. 5. Effects of CRYM on the efflux of iodothyronine sulfates. COS1 cells were transfected with 5 pcDNA3 or pcDNA3.hSLC10A1 with or without pSG5.hCRYM. Cells were incubated for 30 min 6 with T3S (A) or T4S (B). After brief washing, cells were incubated (5-30 min) with efflux medium, 7 containing $1 \%$ BSA, and subsequently processed as described in Materials and Methods. 8 Significances represent values obtained in cells expressing hSLC10A1 with hCRYM versus 9 hSLC10A1 without hCRYM. 1\% uptake represents uptake of 10 pmol of incubated substrate. Cellular 10 protein amounts to $\sim 3 \mathrm{mg}$ in all wells. $* \mathrm{P}<0.05$; ** $\mathrm{P}<0.01$; *** $\mathrm{P}<0.001$. 


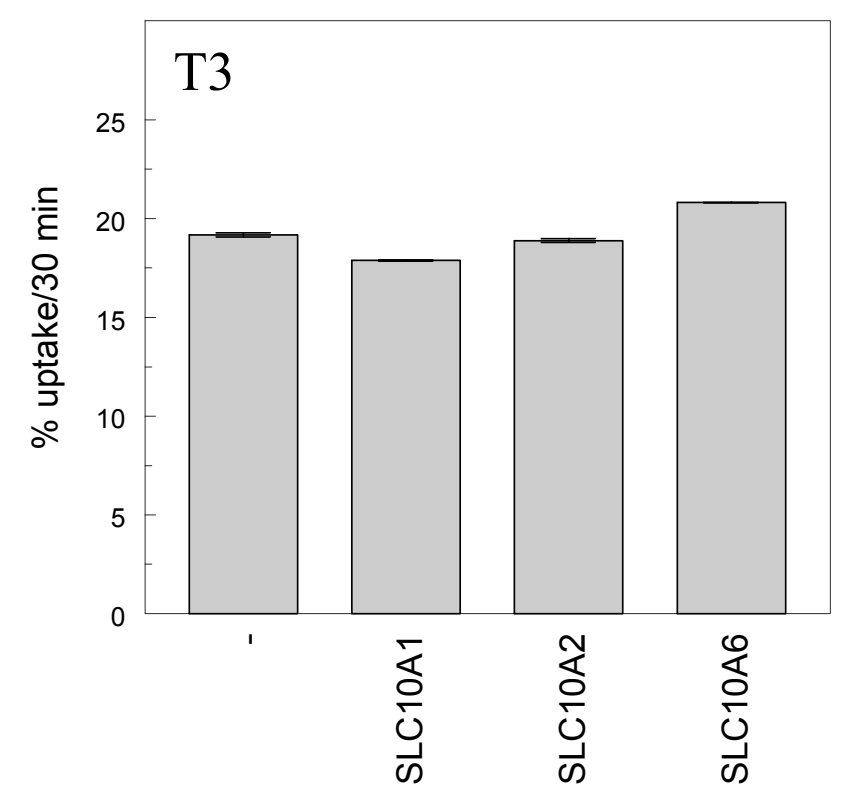

Fig. 1A

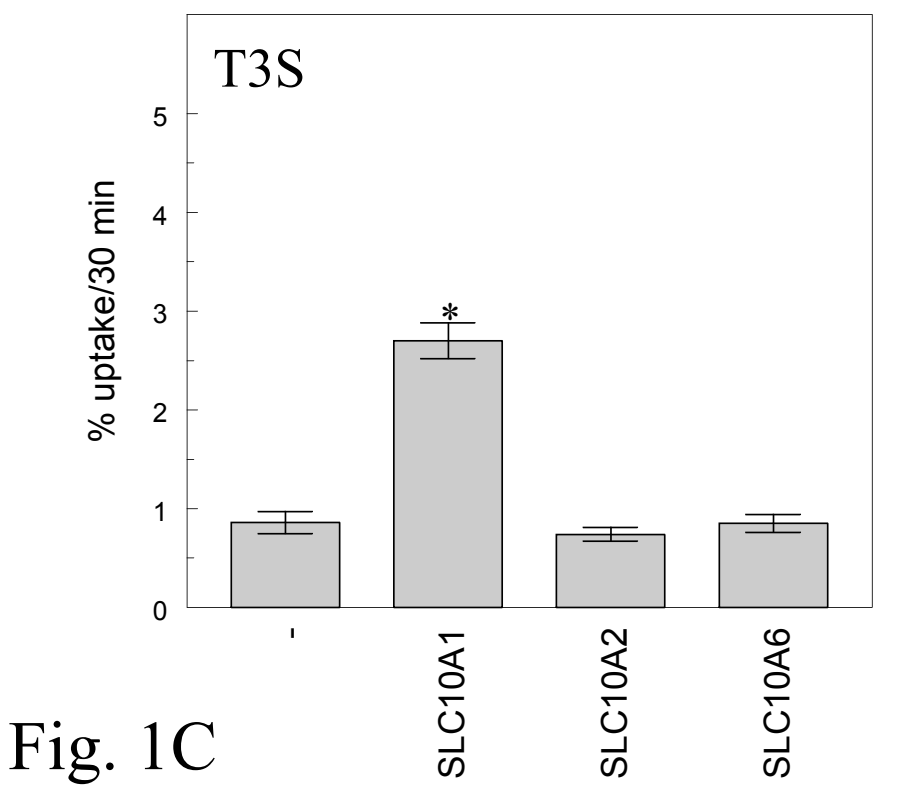

Fig. 1B

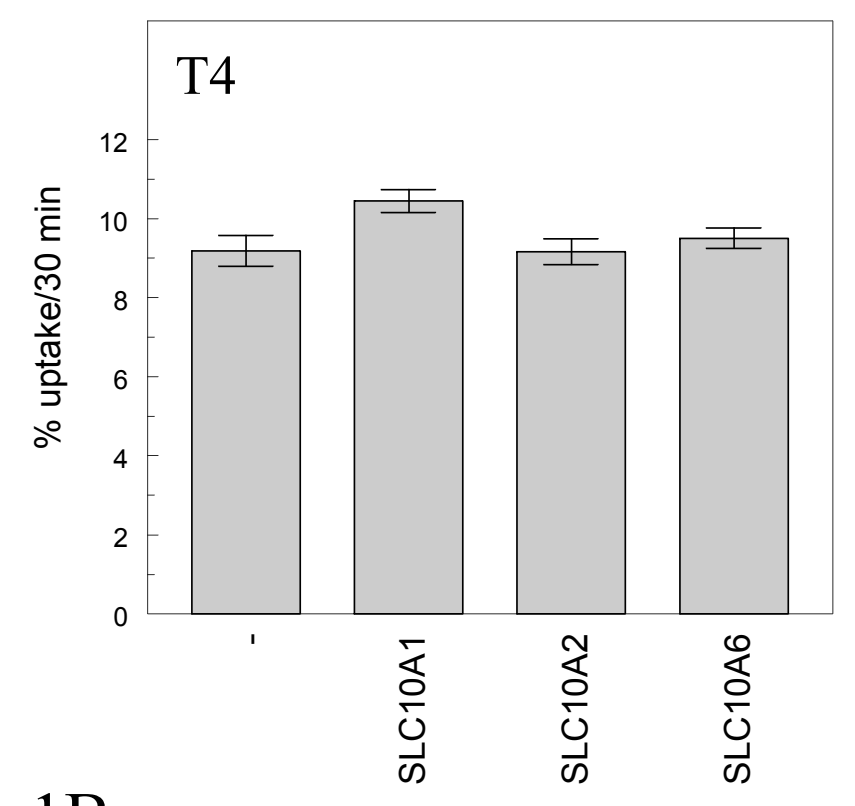

$\uparrow$

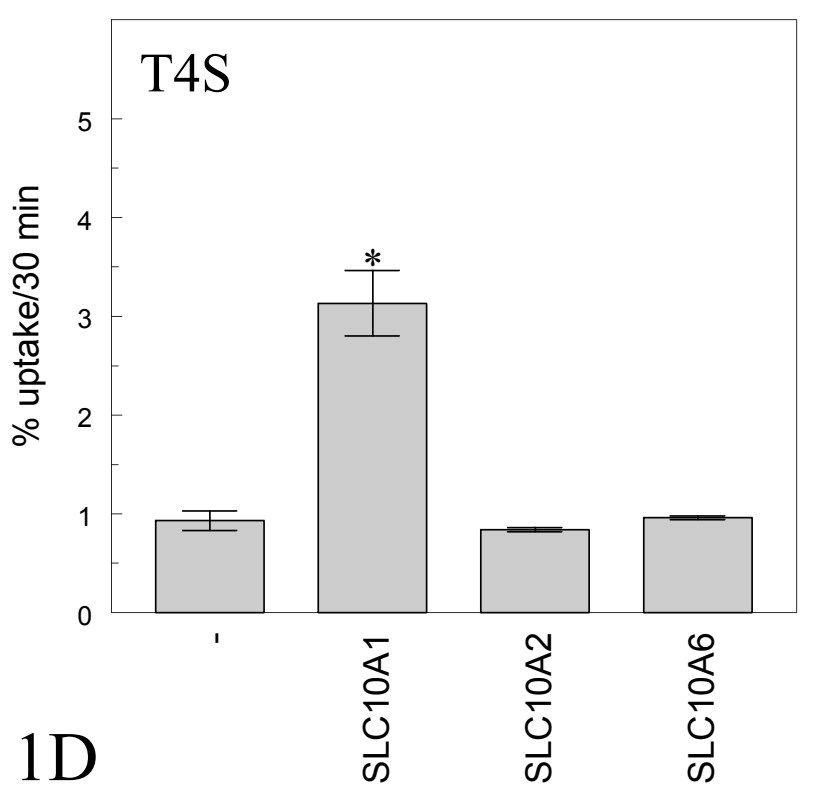




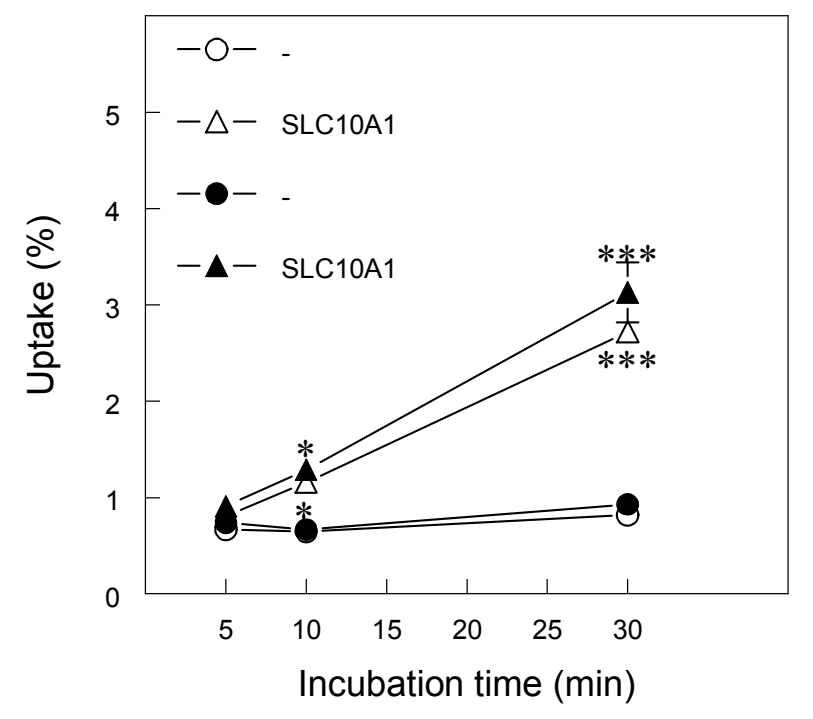

Fig. 1E

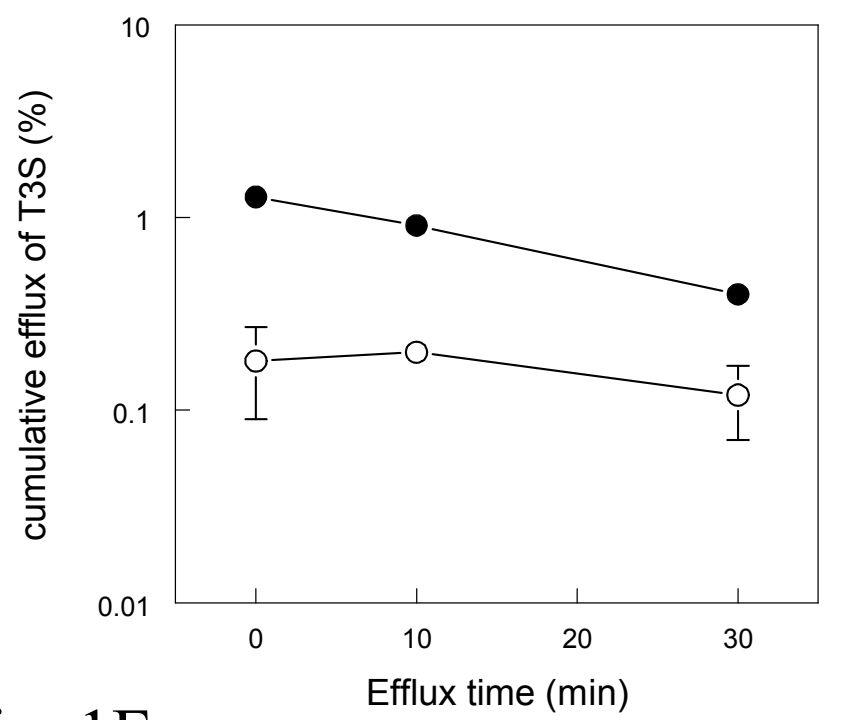

Fig. 1F

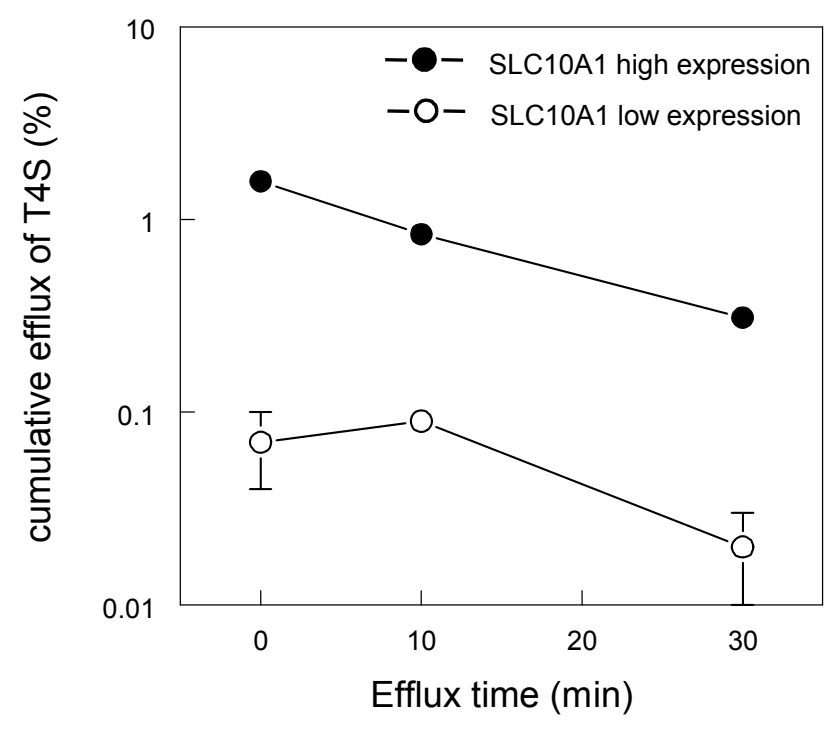

Fig. $1 \mathrm{G}$ 

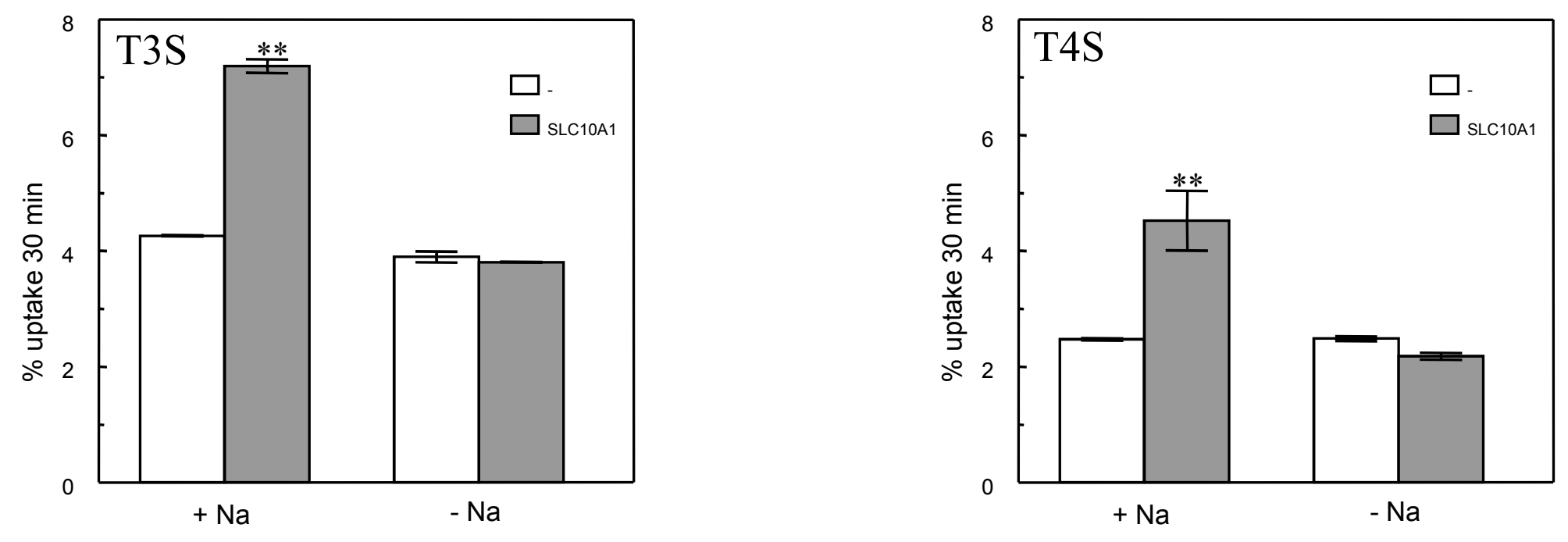

Fig. $1 \mathrm{H}$

Fig. 1I 


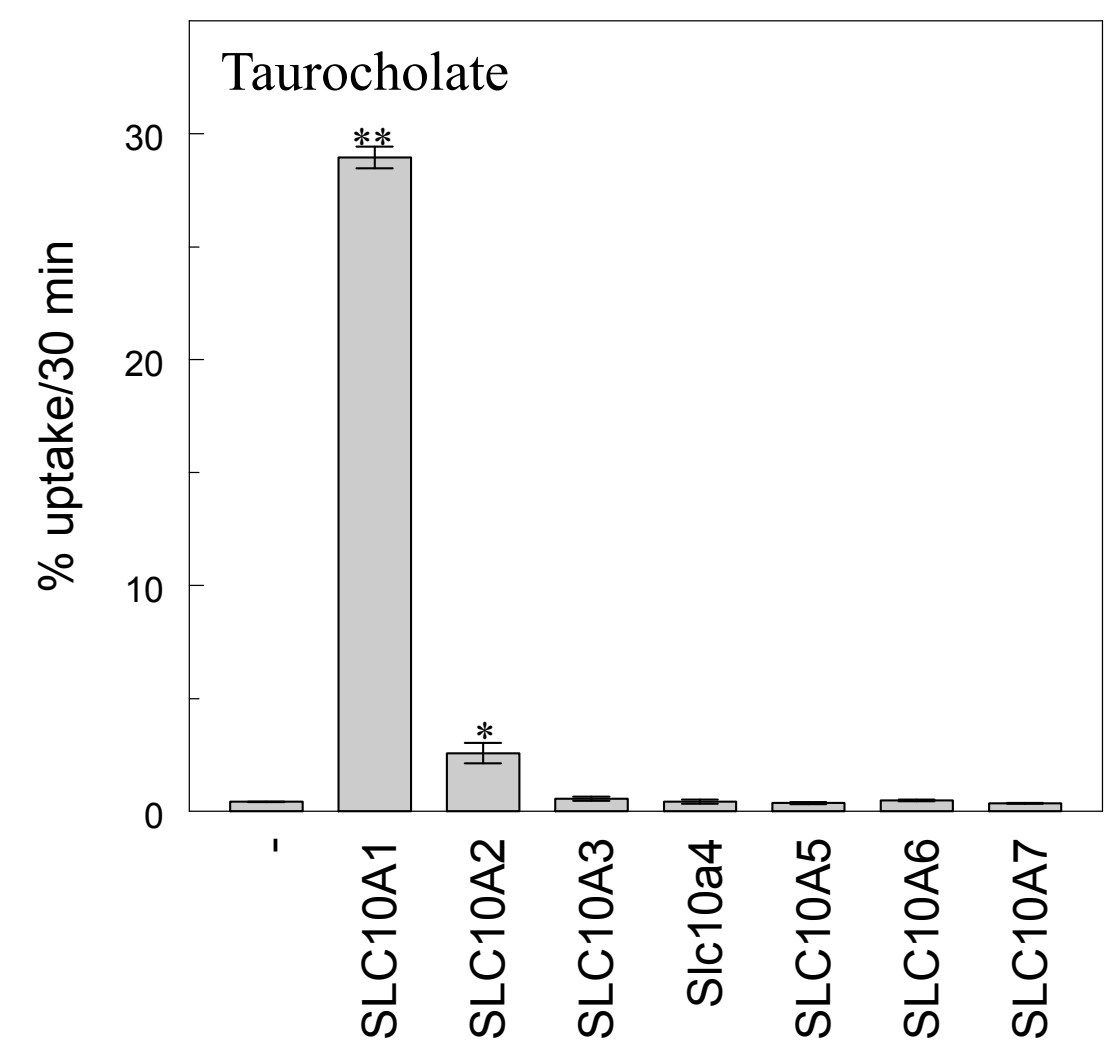

Fig. 2 


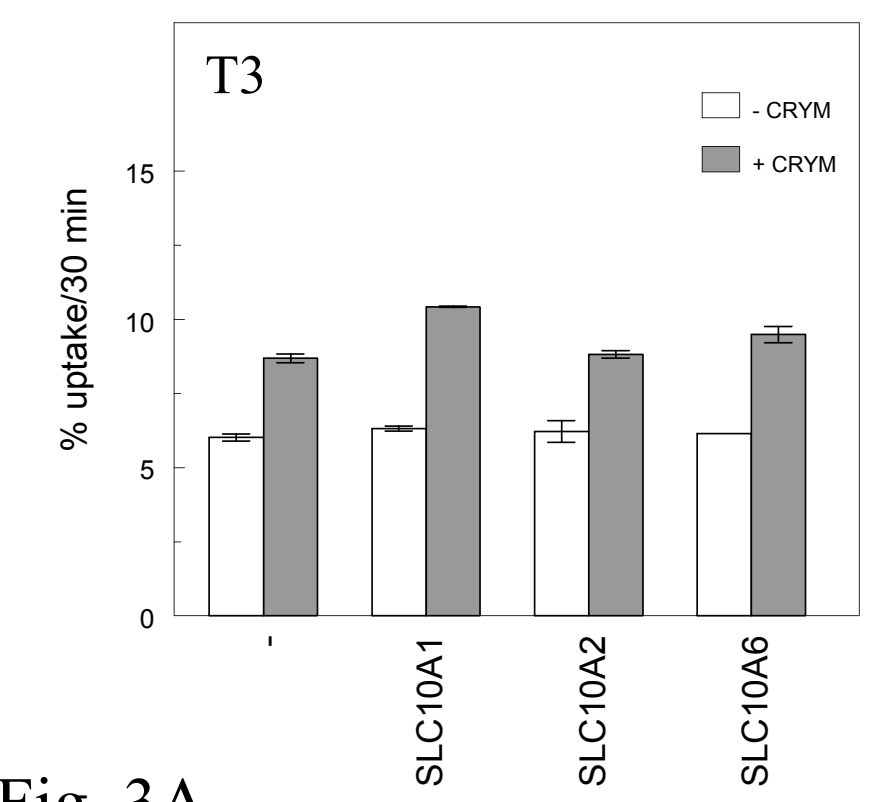

Fig. 3A

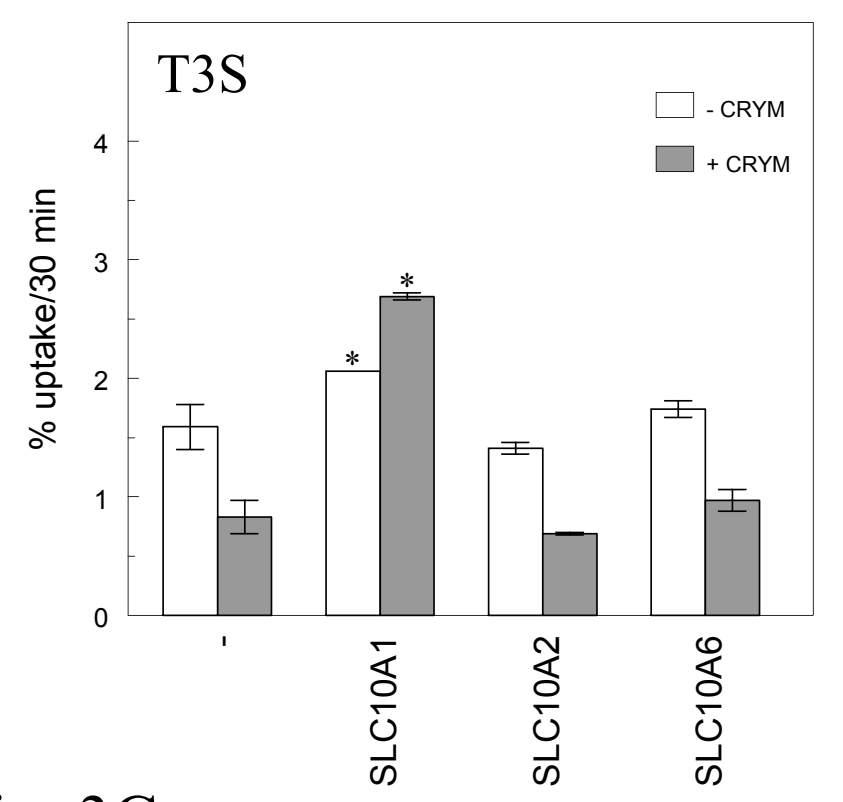

Fig. 3C

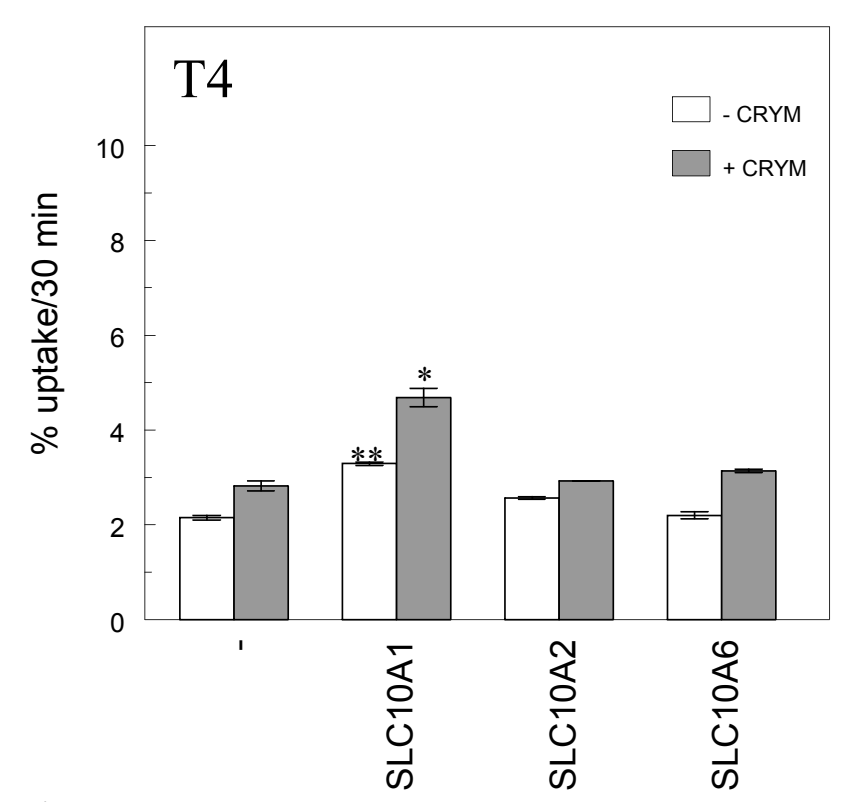

Fig. 3B

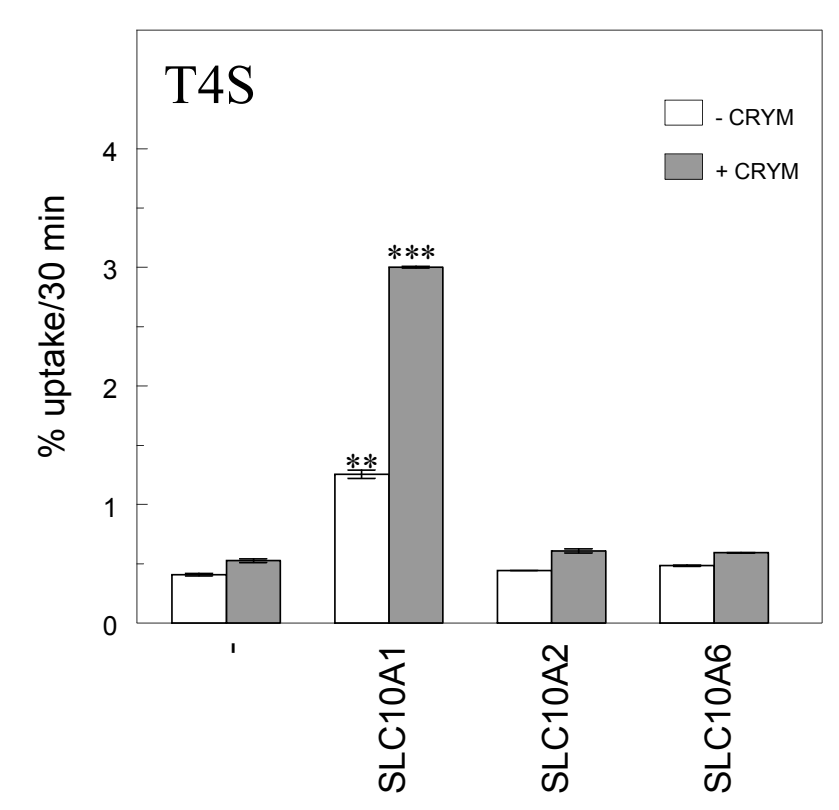

Fig. 3D 

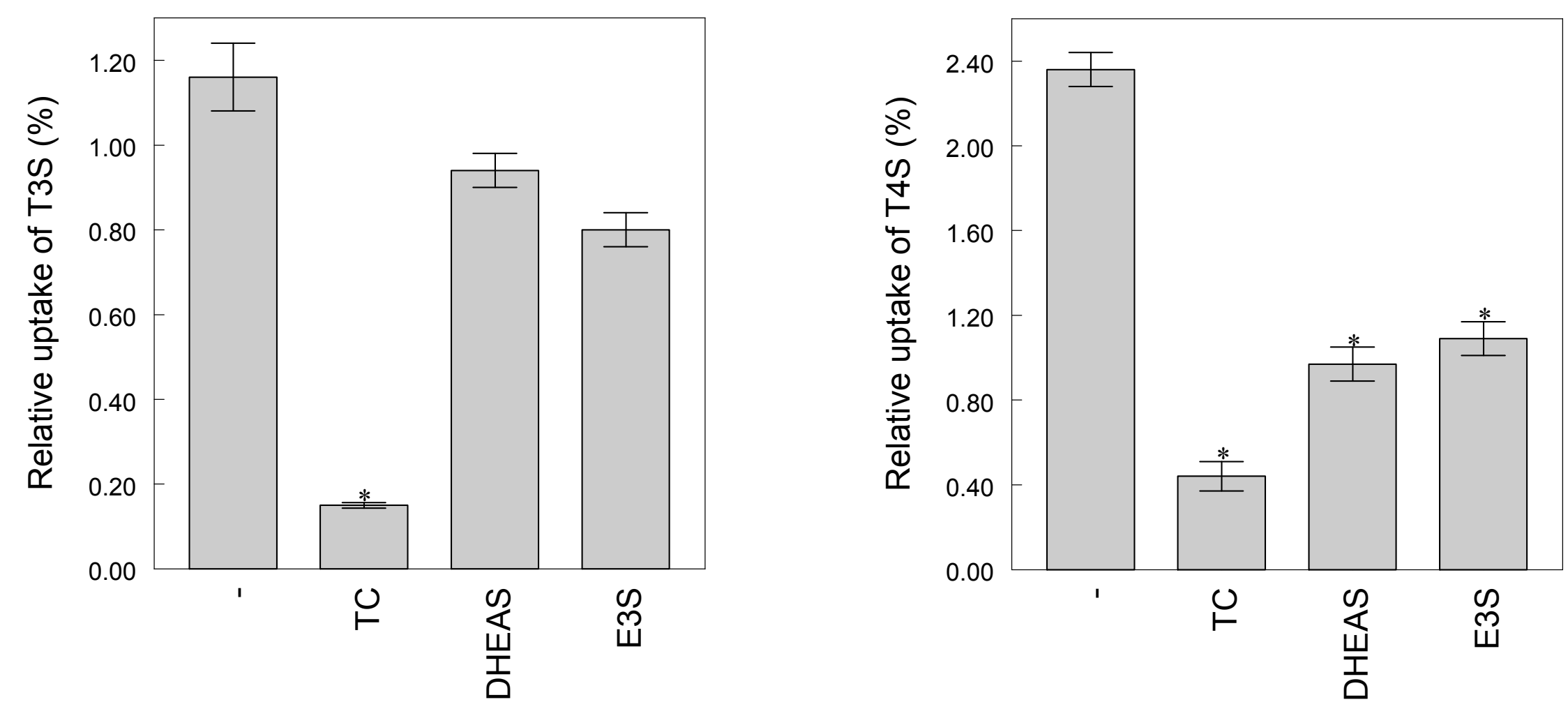

Fig. 4A

Fig. 4B 

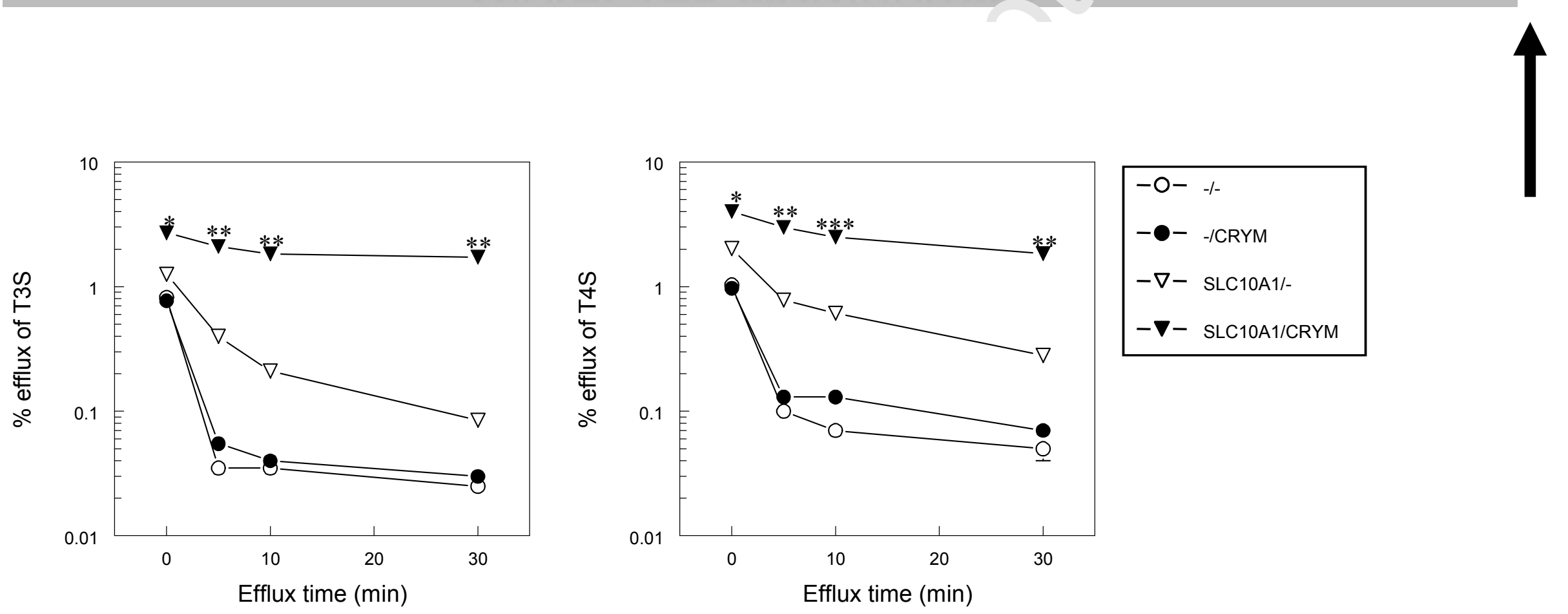

Fig. 5A

Fig. 5B 